\section{Questión}

Periodismo / Comunicación ISSN 1669-6581
- Av. $44 \mathrm{~N}^{\circ} 676,1^{\circ}$ piso

CP 1900 - La Plata - Argentina

www.perio.unlp.edu.ar/question

Es momento de actuar. Decisión, proyecto, condiciones, iniciativa

Santiago Liaudat

DOI: https://doi.org/10.24215/16696581e294

\title{
Es momento de actuar
}

Decisión, proyecto, condiciones, iniciativa

\section{It's time to act}

Decision, project, conditions, initiative

Santiago Liaudat / santiago.liaudat@gmail.com

Prof. de Filosofía (UNLP). Magíster en Ciencia, Tecnología y Sociedad (UNQ). Especialista en Estudios Latinoamericanos (UFJF-Brasil). Diplomado Universitario en Filosofía de la Liberación (UNJu). Profesor Titular Ordinario de Introducción a la Filosofía (FTS-UNLP). Investigador del Laboratorio de Estudios en Cultura y Sociedad (LECyS-FTS-UNLP) y del Centro de Ciencia, Tecnología y Sociedad (CCTS, UMai). Integrante de la Cátedra Libre Ciencia, Política y Sociedad (UNLP) José A. Sbattella / jsbattella@gmail.com

Lic. en Economía (UNLP). Director del Instituto de Estudios Fiscales y Económicos (IEFE). Ex Profesor Titular de Economía II (FaHCE-UNLP). Ex Presidente de la Unidad de Información Financiera (UIF). Ex Representante de Argentina en el Grupo de Acción Financiera Internacional (GAFI). Ex presidente de la Comisión Nacional de Defensa de la Competencia (CNDC). Ex Director General de Aduana (DGA). Ex Director General de la Dirección Nacional de Impuestos (DGI). Ex Director General de Rentas de la Provincia de Buenos Aires (DGR). Contacto:

Audacia y más audacia

En los últimos cien años atravesamos grandes conmociones globales. Cada una de ellas motivó un conjunto de acontecimientos perdurables. A la Primera Guerra Mundial le siguieron la Revolución Rusa, la Marcha sobre Roma y el fin de cuatro imperios dinásticos. Al crack financiero del '29 le sucedieron la Gran Depresión, el ascenso de Hitler al poder y el keynesianismo económico. La Segunda Guerra Mundial generó las condiciones para la Revolución China, la descolonización africana y el peronismo en Argentina. La crisis de 
acumulación capitalista de los '70 favoreció el surgimiento del neoliberalismo, las dictaduras del Cono Sur y la revolución tecnológica. La caída de la Unión Soviética dio vía libre a la globalización, la precarización del trabajo y la crisis de los Estados nacionales. El atentado a las Torres Gemelas propició medidas económicas que condujeron a la Gran Recesión de 20082009 y favorecieron el boom de las commodities que sentó las bases materiales para la década ganada en América Latina.

Hoy estamos transitando uno de esos parteaguas en la historia. Vivimos en un mundo impredecible hace tan solo cuatro meses. La ansiedad y el desconcierto sobre las consecuencias de la situación actual nos dominan. Esta incertidumbre atraviesa diferentes planos encadenados entre sí. En materia sanitaria, desconocemos cómo evolucionará la pandemia, cuándo estarán disponibles la vacuna y los fármacos terapéuticos, cuánto van a durar las cuarentenas y los cierres de fronteras. En lo económico, ignoramos cuán profunda será la recesión global y cómo se reorganizarán el comercio internacional y las cadenas de valor. Un quiebre financiero generalizado es una posibilidad ante el riesgo de una cesación de pagos con efecto dominó. En el orden de la geopolítica se evidencian reacomodamientos profundos que pueden dar lugar a un nuevo orden global. Percibimos giros ideológicos en relación al Estado, la globalización o la inmigración, que todavía no adquieren su formulación definitiva. En términos sociales, es indudable que aumentará la pobreza y la indigencia producto de la parálisis económica, pero no sabemos cuánto se acrecentará ni cómo reaccionarán las personas asediadas por la miseria y la enfermedad.

En una poética metáfora sobre el período de transición en una revolución, Antonio Gramsci afirmó: "El viejo mundo se muere. El nuevo tarda en aparecer. $Y$ en ese claroscuro surgen los monstruos". La sensación que tenemos es esa, con una pequeña pero gravitante diferencia. El tiempo de crisis -tiempo umbral entre lo viejo y lo nuevo- hace surgir tanto los engendros como las ilusiones, las monstruosidades y las esperanzas. La historia nos muestra que en los momentos de trance se movilizan profundas energías que pueden condensarse tanto en un sentido progresivo como en uno regresivo. Los acontecimientos se espesan como nubarrones de tormenta o como luces del alba.

Sobre ese océano de perplejidades lo atávico del ser humano aflora. Por un lado, es terreno fértil para discursos del odio y el miedo, dos instintos básicos de supervivencia, que sazonados con dosis de chovinismo o fundamentalismo religioso, pueden dar lugar a situaciones atroces. 
Pero, por el otro lado, florecen sentimientos comunitarios y solidarios y vemos renacer al viejo y despotricado Estado en sus facetas de asistencia social, intervención económica y orientación de la vida colectiva. En esa encrucijada nos encontramos. La resultante en cada punto de tensión será producto de particulares circunstancias locales: correlaciones de fuerzas, condiciones materiales, grados de acumulación, calidad de los liderazgos, memorias colectivas. Lo que es seguro es que no hay vuelta atrás, no hay "retorno a la normalidad". Porque el mundo no será el mismo pos-pandemia.

Ahora bien, no es cierto que todo sea incierto. La voluntad organizada cancela la incertidumbre, la controla. La fuerza colectiva es capaz de orientar el curso de los acontecimientos y producir un futuro deseable. Los seres humanos, condicionados como estamos por las estructuras, tenemos la posibilidad también de actuar. $\mathrm{Y}$, en la hora de la verdad, lo que importa es decidirse a actuar. Quien decide a tiempo corre con ventaja. Quien no decide es empujado como una hoja al viento por los ímpetus de la historia. Por lo que, si no sabemos hacia dónde vamos, sino lo definimos nosotros y nosotras, nos lo definirá la inercia de la realidad. Y ésta se muestra cruel con los dubitativos.

Atreverse a decidir requiere audacia, es siempre un salto al vacío. Cuando estás al borde del precipicio no te queda otra opción. Dice el diccionario: audacia es la capacidad para emprender acciones poco comunes. Desde esa definición, la audacia no es una elección, es una necesidad en estos tiempos. Porque la posibilidad de realizar "acciones comunes" no nos saca del embrollo en que estamos y al que vamos. Por lo tanto, hay dos formas de enfrentar la actual crisis: o la gestionamos tratando de que se calmen las aguas y retroceder lo menos posible, o la aprovechamos para tomar decisiones espinosas y avanzamos lo más posible. En otras palabras, en tiempos extraordinarios, podemos tratar de volver a lo ordinario o provocar un nuevo tiempo extraordinario. Esto último es lo que hicieron los revolucionarios de 1810, Juan Domingo Perón en 1945 y Néstor Kirchner y Cristina Fernández desde 2003. Tomar decisiones inusitadas, a sabiendas de las tensiones que generarían, para provocar transformaciones duraderas.

Dar una meta estratégica al esfuerzo colectivo

Por supuesto no son las mismas las condiciones objetivas y subjetivas en cada momento histórico. Nunca lo son. Su interpretación correcta es parte fundamental del arte de la política. 
Ciertamente, precisamos conocer y comprender la situación estructural para actuar eficazmente.i Pero no olvidemos que las condiciones objetivas disponen, pero es la voluntad organizada la que propone.

Si dejamos de lado esta noción, podemos paralizarnos. El análisis crudo de las tendencias de la realidad suele ser angustiante, ya que la única actitud intelectual honesta es ser pesimista. Ser optimistas implicaría ingenuamente reproducir alguno de los discursos legitimadores del imperio o el capital concentrado. Pero, al necesario pesimismo de la inteligencia le oponemos un imprescindible optimismo de la voluntad. Voluntad de vida frente a la explotación, de sentido frente a la alienación, de autodeterminación frente a la dominación. Voluntad colectiva que, movilizada y organizada, ha conquistado todos los derechos y libertades que gozamos. Y, si de soñar un mundo mejor se trata, hemos de hablar entonces de cómo movilizar y organizar políticamente esa fuerza social capaz de torcer el rumbo inercial de la realidad. El primer elemento, sin dudas, es orientar y dar unidad detrás de miras de largo alcance que den motivo a los esfuerzos y sacrificios cotidianos. Una concepción estratégica sin la cual nos movemos erráticos en el mar de lo coyuntural. Esa idea capaz de movilizar corazones y mentes en un sentido progresivo es lo que llamamos Proyecto Nacional.

Corría junio de 1944 y Juan Domingo Perón asistía a la Universidad Nacional de La Plata para inaugurar la Cátedra de Defensa Nacional. Ya estaba decidido por ese entonces el resultado de la conflagración bélica más sangrienta de la historia. Se auguraban tiempos de paz. Sin embargo, el coronel Perón disertaba sobre el arte de la guerra. ¿Por qué motivo? A causa de que entendía que luego de "la crisis más extraordinaria que haya presenciado la humanidad" (la Segunda Guerra Mundial), el "mundo ha de estructurarse sobre nuevas formas, con nuevo contenido político, económico y social". Y, a continuación, aportó lo fundamental de un programa estratégico basado en la movilización de las fuerzas sociales, productivas e intelectuales del país para posicionarse frente a un escenario incierto.

Resumidamente, propone al Estado y la comunidad como actores protagónicos de la transformación de una Argentina primarizada y semicolonial (por lo tanto, "indefensa" no solo militar, sino económica y políticamente) en una nación soberana, basada en la actividad industrial, con bases científicas y tecnológicas sólidas, capaz de preservar su carácter pacífico en los tiempos turbulentos que preveía. La independencia económica y la justicia social, logradas durante su gobierno, se siguieron como teoremas de esos axiomas políticos 
fundamentales. El corolario institucional más alto de aquellas ideas estratégicas: la Reforma Constitucional de 1949.

En la actualidad, y aunque los tambores de la guerra truenan cada tanto en boca de los mandamases, afortunadamente no es un contexto bélico el que nos rodea.ii Pero, a nuestra manera, debemos prepararnos para la lucha: contra la miseria, contra el fatalismo y contra la dependencia. O mejor, por la vida, por la democracia, por la autodeterminación. Para lo cual, al igual que propuso Perón en aquel discurso memorable, debemos alinear las fuerzas productivas, sociales e intelectuales detrás de grandes metas colectivas sintetizadas en un Proyecto Nacional.iii

\section{Condiciones para avanzar}

Si actuamos con decisión, el momento es propicio para inclinar la balanza a favor de las mayorías sociales y la soberanía nacional. La pandemia ha golpeado duramente los bolsillos, ha generado una enorme aflicción social y ha producido un cuadro general de incertidumbre angustiante. Todo ello es cierto. Pero también ha desencadenado procesos que pueden ser canalizados favorablemente con audacia política:

Fin de la globalización. La fragilidad en que se encontraron los países frente al corte abrupto de las redes de suministro condujo a un cuestionamiento a la deslocalización productiva promovida por el capitalismo globalizado. Lo cual reinstala la necesidad del autoabastecimiento en manufacturas e insumos críticos para la sociedad. Frente a la evidencia de la dependencia externa, se fortalecen las ideas de autonomía nacional y regional. Lo que pone en cuestión al lucro como único motor de la actividad económica. Aparece a su lado un criterio de mayor importancia: garantizar la reproducción social.

Descrédito del neoliberalismo. Con el fin de la globalización caen también sus recetas económicas asociadas. Las reformas de los Estados, caracterizadas por la privatización, la descentralización y la tercerización, dejaron a los países desguarnecidos. La debilidad de los sistemas sanitarios y los sistemas de seguridad social son muestra palpable de ello. Podemos hacer leña del árbol caído y, a fuerza de una pedagogía de la repetición, promover un nuevo consenso: ¡Nunca más al neoliberalismo!

Fortalecimiento del Estado. Ante la incertidumbre producida por la pandemia los pueblos del mundo no acudieron al mercado buscando respuestas, sino que apelaron a sus Estados. En la 
medida en que da respuesta, el Estado se re-legitima como organismo de regulación social frente al mercado. Para impulsar cambios en nuestro país, esto es un plafón invaluable. Nos da legitimidad para hacer un uso más firme de los instrumentos de regulación económica. Sin necesidad de reformas legislativas, con la mera aplicación de normativas vigentes, es mucho lo que podría hacerse en este momento en áreas sensibles como elusión y evasión fiscal de los grandes capitales y delitos de colusión, formación de precios y otras malas prácticas comerciales.

Responsabilidad compartida sobre la salud colectiva. La cuarentena generó un loable sentimiento de cuidado social, una reafirmación de la salud como derecho y la salud pública como necesidad. Estas dimensiones, importantes de por sí, se vinculan con un aspecto más profundo: la comunidad se siente responsable por la vida de sus miembros. Parece una perogrullada pero no lo es cuando observamos el comportamiento en sociedades que se mimetizaron completamente con la concepción neoliberal, mercantilista e individualista. Este buen sentido que anida en el corazón de nuestro pueblo debe ser protegido y servirá de punto de apoyo para las transformaciones más profundas.

Crecimiento de la autoridad presidencial. Además del Estado, las sociedades buscaron liderazgos que las guíen. Por supuesto, y dado el papel del gobierno en la dirección del Estado, lo usual ha sido la referenciación en figuras políticas (normalmente los presidentes, pero donde esas figuras fallaron, aparecieron otros líderes sociales o políticos). El adecuado ejercicio del liderazgo en medio de la crisis sanitaria otorgará un enorme capital político a la autoridad en ejercicio. Esto, que es positivo o negativo de acuerdo a quien ejerza el poder en cada territorio, en el caso argentino nos coloca en una muy buena posición. El presidente Alberto Fernández ha logrado un alto grado de consenso, atravesando incluso la grieta social exacerbada por los medios masivos de comunicación desde hace una década.

Sentimiento de unidad nacional y nuevo antagonismo. Por lo dicho en el punto anterior, contamos con una excelente oportunidad para fortalecer la idea del proyecto nacional como expresión de la unidad nacional. De la mano con una repolarización del debate y un nuevo antagonismo: ya no entre fracciones del pueblo, entre el campo y la ciudad o entre conurbano e interior, sino entre quienes trabajan y quienes se aprovechan del trabajo ajeno, quienes construyen la patria y quienes viven a expensas de ella (los grandes grupos económicos, los pulpos financieros, los evasores, los vendidos a intereses foráneos). El necesario discurso de 
unidad nacional no debe confundirse con evitar el antagonismo. El conflicto es inherente al ser humano y, por lo tanto, a la política. Y si el Proyecto Nacional no define un antagonismo, nos lo impondrán los grupos concentrados estableciendo la línea de corte donde mejor les convenga. Vivir con lo nuestro. Siempre que hubo cortes de suministro internacional se generaron condiciones que favorecieron a la industria local. Pero a las condiciones favorables hay que acompañarlas con políticas activas de protección y promoción de la actividad manufacturera. Tenemos capacidades humanas, técnicas y materiales sub-aprovechadas. En una primera etapa puede significar productos de menor calidad o mayor precio que lo que se consigue en el mercado global. Pero privilegiar la producción nacional tiene efectos en cascada tanto a nivel económico (mayor densidad y complejidad productiva, generación de empleo, etc.) como a nivel cultural y político (una mayor autoestima nacional, soberanía, etc.). Para lo cual hay que ir más allá del tradicional paradigma del desarrollo medido exclusivamente en términos economicistas (según el cual crecimiento de los indicadores macroeconómicos es igual a desarrollo).

Orientación de la ciencia, la tecnología y la educación con fines nacionales. Las emergencias permiten aquello que parecía imposible. El sector científico y tecnológico, por lo general reacio a una firme orientación estatal de la agenda de investigación, se puso en marcha detrás de metas bien claras. ¿Por qué no aprovechar el impulso y dar un paso definitivo en ciencia y tecnología hacia una política guiada por objetivos de desarrollo social y económico? En el mismo sentido se podría plantear la necesidad de planificar la educación superior en términos de las necesidades nacionales. Lo cual supone discutir composición de la oferta de estudios y el perfil profesional al que debe abonar la formación universitaria.

Una eventual crisis de deuda mejora las condiciones para negociar. La deuda asedia por igual a casi todos los países del mundo. El actual escenario de parálisis global e incertidumbre económica pone en riesgo el cumplimiento de los compromisos externos de parte de los Estados. El riesgo de una crisis global de deuda pone en mejores condiciones a la Argentina para negociar este aspecto crítico que condiciona toda nuestra política económica. Los acreedores privados -presionados por los Estados y organismos multilaterales- deberán ser más permisivos en las negociaciones para evitar que se corte la cadena de pagos y se genere una crisis sistémica. Y la Argentina puede volver a erigirse, como lo hizo durante el gobierno de Cristina Fernández, como portavoz de los países víctimas de la especulación financiera. 
Debilitamiento norteamericano-europeo y geopolítica multipolar. Los procesos de autodeterminación nacional en América Latina fueron casi siempre sofocados por la iniciativa de los países centrales, especialmente la estadounidense. Pero la lamentable política que asumió Washington frente a la pandemia ha significado un enorme daño al prestigio norteamericano y su capacidad de liderazgo global. La imagen de sus socios europeos también está fuertemente resentida. En paralelo, China y sus aliados mejoraron su posición geopolítica mediante la asistencia a los países afectados y una demostrada capacidad para hacer frente a la crisis sanitaria. Todavía está por verse si el retroceso de los Estados Unidos se traduce en una crisis de hegemonía. Pero, sin dudas, como resultado de la pandemia se consolida un mundo multipolar. Lo cual constituye una ventana de oportunidad para los países dependientes, como la Argentina, al permitir un mayor margen de juego diplomático, un acceso beneficioso a tecnología, bienes de capital y recursos financieros, y un posible resguardo frente a la injerencia externa en asuntos domésticos.

\section{Retomar la iniciativa}

El ex presidente Mauricio Macri, carente de méritos como estadista, sin embargo nos dio una lección en política. En poco tiempo, a fuerza de Decretos de Necesidad y Urgencia, reformó ministerios, desmanteló conquistas como la Ley de Medios, puso en jaque al Estado de Derecho. Así arrasó en meses lo que construimos en años. Una verdadera política-relámpago que nos dejó descolocados. Incluso ahora, en la oposición, luego de resultados deplorables durante su gobierno, el bloque neoliberal continúa con la iniciativa, desde los medios de comunicación a las protestas callejeras (cacerolazos, tractorazos), marcando agenda, estableciendo límites.

Hoy, como ayer, somos gobierno. Una vez más nos toca sacar a flote un barco hundido. A la emergencia económica y social se le suma un Estado endeudado y debilitado. Y sobre Ilovido... ¡llega la pandemia!... Imprevisible, tenebrosa y de efectos inciertos... Caída abrupta de la actividad económica, altos costos sociales... Entonces, ¿qué hacer? Las posibilidades de un avance timorato, pautado, gestionado, se agotan. Por un lado, la derecha no perdona. Por el otro, las opciones se reducen. En ese escenario hay condiciones favorables para, con algo de audacia, retomar la iniciativa. Circunstancias excepcionales habilitan medidas excepcionales. 
Caminos sin los cuales no lograremos sacar a los millones de compatriotas de la pobreza y a la Argentina de la dependencia.

Iniciativa no es voluntarismo o maximalismo. Es recuperar los aprendizajes realizados durante el último gobierno popular y los años en la oposición. Lecciones que nos indican que sin profundizar los cambios se cae en un cuello de botella que ahoga el crecimiento y la inclusión. Se trata de un proceso estructural que en el mediano plazo se expresa como disgusto social y se canaliza políticamente contra el Proyecto Nacional. En el peor escenario significa una derrota electoral, la pérdida del gobierno y vuelta a empezar.

Actualmente el Estado cuenta con una legitimidad renovada para avanzar en la transformación social y productiva de la nación. El estado de shock puede producir una mayor permeabilidad social a diversas propuestas. No desaprovechemos el momento. Un país se puso en marcha en la lucha contra la pandemia, como antes lo hizo en la lucha contra el hambre, y anteriormente para vencer en las urnas al neoliberalismo. Fortalezcamos ese alineamiento de fuerzas sociales, productivas e intelectuales detrás de nuevas iniciativas. Convoquemos a la sociedad y en especial a las organizaciones libres del pueblo (sindicatos y movimientos sociales) a ser parte de la transformación. No perder las calles es una premisa. Pero además estas estructuras orgánicas pueden complementar -de hecho lo hacen- los esfuerzos del gobierno, tratando de garantizar medidas impulsadas en áreas sensibles como el control de precios o el sector bancario. $Y$ deben ser, como factor de presión, la fuerza que nos empuje hacia adelante.

Los resortes del poder concentrado siguen intactos. Manejan la gran prensa. Son amos y señores en el poder judicial. Se pasean orondos al no sentir represalias por los desmanes que cometieron. Continúan especulando con el dólar y los precios. Concentran el poder económico. Banqueros, políticos, jueces, periodistas y empresarios que lucraron a expensas del Estado y la sociedad argentina. ¿Por dónde empezar? Lo primero es dar un mensaje claro: hay que acabar con la impunidad de los especuladores y quienes desde la función pública se prestaron a los tejes y manejes del capital financiero. Todo el peso de la ley debe caer sobre estos miserables.

Fuimos testigos de la arremetida judicial que hicieron contra funcionarios del gobierno de Cristina Fernández de Kirchner. No les importó el derecho al debido proceso, apelaron al espionaje político, hicieron verdaderos linchamientos mediáticos mediante noticias falsas. En 
fin, toda forma de amedrentamiento sobre quienes encabezaron las políticas más osadas del período anterior. ¿No vamos a hacer nada frente a esta violación de las garantías constitucionales? Esta impunidad puede ser un mensaje paralizador para los funcionarios del actual gobierno. ¿Quién se atreverá a tomar las medidas de fondo y confrontar con los factores de poder? Si nos van a atacar de todos modos, es preferible que sea por exceso y no por defecto, por lo que hicimos y no por lo que dejamos de hacer. Presionar y no dejarse acorralar. Retomar la iniciativa con las herramientas que la Constitución Nacional nos da en el ejercicio de gobierno. Tenemos el poder, usémoslo.

Por último, somos humanos, demasiado humanos. Necesitamos creer en algo para vivir. Todos los pueblos precisan de una fe que le dé sentido a los días, a los sufrimientos y las alegrías. La pandemia nos deja una globalización agonizante y un capitalismo salvaje que no ilusiona. No emana aún un mito sustitutivo desde las usinas del pensamiento del Norte y en ese vacío tenemos la posibilidad -en verdad, la necesidad- de proponer un proyecto universal desde el Sur. San Martín escribió: "Necesitamos pensar en grande: si no lo hacemos, nosotros tendremos la culpa". Salir de la pasividad, el seguidismo o el localismo intelectual y político, y atrevernos a soñar. Si, como decía Don Arturo Jauretche, "lo nacional es lo universal visto por nosotros", entonces el Proyecto Nacional debe ser una propuesta de humanidad, de sociedad y de orden global.

Sin mística no hay esperanza, sin espíritu de grandeza no hay confianza. Así lo entendía Perón al plantear la doctrina justicialista como una propuesta filosófica, económica, política y social de contenido humanista que la Argentina convidaba al mundo. Así lo entendió Néstor Kirchner cuando nos propuso un sueño en un país desahuciado. Se hace patente la necesidad de crear un nuevo mito movilizador. Podrá llamarse nuevo pacto social o justicialismo del siglo XXI, liberación o socialismo nacional, como sea. Lo importante ahora es ponerse en marcha.

\section{Bibliografía}

Bilmes, J., Dubin, M. \& Liaudat, S. (2020). Pandemia o la continuación de la guerra por otros medios. En libro del Concurso de Ensayos Breves "Un fin del mundo mejor es posible". Buenos Aires: Instituto Democracia. En prensa. Disponible en: https://www.institutodemocracia.com.ar/ 
Liaudat, S. \& Sbattella, J. (Comps.) (2019). La teoría de la desconexión de Samir Amin: una opción para Argentina frente a la crisis global. Buenos Aires: Colihue. Disponible en: http://online.fliphtml5.com/gcxps/qzsu/

Ramonet, I. (2020). Ante lo desconocido: la pandemia y el sistema-mundo. Le Monde Diplomatique, edición Cono Sur, abril de 2020. Recuperado de: https://www.eldiplo.org/notasweb/la-pandemia-y-el-sistema-mundo/ (última visita el 29/04/2020).

Sbattella, J., Barrera, F., Bona, L., Noguera, D. \& Quesada, J. (2020). Informe 187 del Instituto de Estudios Fiscales y Económicos. La Plata: IEFE. Recuperado de: https://www.iefe.org.ar/2020/03/16/informe-iefe-187/ (última visita el 29/04/2020).

Van Creveld, M. (1991). The Transformation of War: The Most Radical Reinterpretation of Armed Conflict Since Clausewitz. New York: Free Press.

Notas

\begin{abstract}
i Dado que no es el objetivo de este artículo, no nos detendremos en este punto. En trabajos recientes hemos analizado las consecuencias que la pandemia ha tenido -hasta ahora- en las dimensiones económico-financieras y geopolíticas (Sbattella y otros, 2020; Bilmes, Dubin \& Liaudat, 2020). Para un análisis exhaustivo de los diferentes efectos de la pandemia recomendamos Ramonet (2020).

ii Esta afirmación, sin embargo, debe ser matizada de acuerdo a los cambios en materia de doctrina militar y de defensa. El alto poder destructivo y la gran movilidad alcanzados por las Fuerzas Armadas desde la Segunda Guerra Mundial ha sido un disuasivo para la confrontación directa entre grandes potencias (habitual hasta entonces). Se pasó, desde entonces, a lo que se conocería como Guerra de Cuarta Generación, también conocida como Guerra Sucia o de Baja Intensidad: métodos irregulares, guerra psicológica, terrorismo, etc., en la que se evita el conflicto a campo abierto (Van Creveld, 1991). Actualmente, los EEUU y la OTAN postulan la existencia de una nueva etapa que denominan Guerra de Quinta Generación (también Ilamada Guerra Sin Límites) basada en la manipulación de masas utilizando métodos tecnocientíficos avanzados (neurociencias, big data, fake news, etc.) combinado con operaciones de hostilidad en todos los planos (desde boicots económicos y diplomáticos hasta ataques sobre la infraestructura tecnológica de un país). Las agresiones que sufren desde hace décadas Venezuela, Cuba e Irán constituyen paradigmas de aplicación de estas técnicas de desgaste. Cabe aclarar, de todos modos, que un tipo de guerra no suplanta al otro. Y puede darse la superposición de métodos bélicos de tercera, cuarta o quinta generación. Por ej., las múltiples operaciones sobre Siria desde 2011 hasta la actualidad.

iii Dado que no es el motivo de este artículo dejamos de lado un elemento central del discurso de Perón: la cuestión militar y de defensa. Existe un tabú en el campo popular argentino hacia este tema estratégico luego del genocidio cometido por las Fuerzas Armadas y el rechazo social pos-dictadura hacia los métodos de lucha armada (expresados en el repudio al copamiento del cuartel de La Tablada en 1989). Entendemos que es hora de afrontar este debate sin el cual las posibilidades de supervivencia de un Proyecto Nacional se ven seriamente comprometidas. El golpe al gobierno de Evo Morales en 2019, tal como lo fue el golpe a Salvador Allende en 1973, es una alerta en ese sentido. El punto de partida puede ser la recuperación de la concepción sanmartiniana (ejército popular de liberación con miras latinoamericanas) y la doctrina de Perón de "la nación en armas", junto con el estudio de las experiencias latinoamericanas, asiáticas y africanas.
\end{abstract}

